\title{
Comparing the Effect of Different Antibiotics in Frozen-Thawed Ram Sperm: Is It Possible to Avoid Their Addition?
}

\author{
Luis Anel-Lopez ${ }^{1,2}$, Marta F. Riesco ${ }^{1,3 *}$, Rafael Montes-Garrido ${ }^{1,2}$, Marta Neila-Montero ${ }^{1,2}$, \\ Juan C. Boixo ${ }^{1,2}$, César Chamorro ${ }^{1,2}$, Cristina Ortega-Ferrusola ${ }^{4}$, Ana Carvajal ${ }^{5}$, \\ Jose R. Altonaga ${ }^{2}$, Paulino de Paz ${ }^{1,3}$, Mercedes Alvarez ${ }^{1,2}$ and Luis Anel ${ }^{1,2}$

\begin{abstract}
${ }^{1}$ Investigación en Técnicas de Reproducción Asistida - Universidad de León, Instituto de Desarrollo Ganadero y Sanidad Animal, University of León, León, Spain, ${ }^{2}$ Department of Veterinary Medicine, Surgery and Anatomy, University of León, León, Spain, ${ }^{3}$ Cellular Biology, Department of Molecular Biology, University of León, León, Spain, ${ }^{4}$ Laboratory of Equine Reproduction and Equine Spermatology, Veterinary Teaching Hospital, University of Extremadura, Cáceres, Spain,

${ }^{5}$ Department of Animal Health, Facultad de Veterinaria, Universidad de León, León, Spain
\end{abstract}

\section{OPEN ACCESS}

Edited by:

Szabolcs Nagy,

University of Pannonia, Hungary

Reviewed by:

Jane Morrell,

Swedish University of Agricultural

Sciences, Sweden

María Ignacia Carretero,

University of Buenos Aires, Argentina

*Correspondence:

Marta F. Riesco

mferrs@unileon.es

Specialty section: This article was submitted to

Animal Reproduction -

Theriogenology,

a section of the journal

Frontiers in Veterinary Science

Received: 21 January 2021

Accepted: 09 March 2021

Published: 07 May 2021

Citation:

Anel-Lopez L, Riesco MF, Montes-Garrido R, Neila-Montero M,

Boixo JC, Chamorro $C$,

Ortega-Ferrusola C, Carvajal A, Altonaga JR, de Paz P, Alvarez $M$ and Anel L (2021) Comparing the Effect of Different Antibiotics in Frozen-Thawed

Ram Sperm: Is It Possible to Avoid Their Addition?

Front. Vet. Sci. 8:656937.

doi: 10.3389/fvets.2021.656937
It is crucial to perform a deep study about the most extensively used antibiotics in sperm extenders. Most of the protocols and concentrations used in ram are direct extrapolations from other species. It is important to establish species-specific antibiotic treatments to optimize their use and if it is possible to reduce the quantity. Previews studies have assessed some aspects of sperm quality in vitro, but this study aimed to go further and assess the effect of three different antibiotic treatments, which are the most extensively used, not only in sperm quality or assessing the inhibitory effect on bacterial growth but also assessing these important parameters of productivity such as fertility, prolificacy, fecundity, and sex-ratio during a freeze-thaw process. Gentamicyn (G) treatment showed the worst results, not only concerning sperm quality but also in the reproductive trials exhibiting a toxical effect at the experiment concentration, and being the most powerful inhibiting bacterial growth. For its part, Lincomicyn-spectinomycin (LS) showed similar results inhibiting bacterial growth but it did not show a detrimental effect either in sperm quality or in reproductive parameters. Penicillin-streptomycin (PS) showed good results in the sperm quality and in the reproductive in vivo trials, but it showed a very poor effect inhibiting bacterial growth probably due to some kind of antibiotic resistance. According to our results, there is not a significant positive relationship between the higher bacterial inhibitory activity of LS and PS samples, and the sperm quality respect Control samples (without antibiotics). In the case of $\mathrm{G}$, which exhibited the most effective as antibacterial, we observed a toxic effect on sperm quality that could be translated on productivity parameters. Our results suggest that the bacterial contamination control in frozen-thawed semen may be possible without the use of antibiotics, although the effects of longer periods of cooling storage and different temperatures of storage need to be further investigated for animal semen. At this point, a reflection about a drastic reduction in the use of antibiotic treatments in sperm cryopreservation is mandatory, since freezing conditions could keep sperm doses contamination within the levels recommended by regulatory health agencies.

Keywords: ovine semen, artificial insemination, antibiotics, fertility, sex-ratio, prolificacy, antibiotic resistance 


\section{INTRODUCTION}

Semen collection and sperm manipulation are not sterile processes, and bacterial contamination, especially environmental and non-pathological but also pathological species, of sperm samples cannot be avoided $(1,2)$. In ram, the final ejaculate collected is usually contaminated at least with bacteria from the technician, artificial vagina, penis, and prepuce. In this way, bacterial contamination could affect not only the sperm quality but also the final yield of the production. The bacteriasperm interaction has been widely studied, especially in human sperm with $E$. coli as a model of contamination concluding that the spermicidal effect is concentration-dependent (3). Several negative effects have been reported from the bacterial contamination on the sperm quality such as the sperm motility impaired by bacterial adhesion and agglutination (4, 5), inducing morphological changes (6) altering the sperm function, increasing the phosphatidylserine translocation and the apoptosis activation (7). In addition, some studies suggest that bacterial contamination may increase the antibodies production affecting the glycocalyx complex in the sperm surface $(3,8)$. To prevent disease transmission in most domestic species, the addition of antibiotics to sperm extenders is mandatory in the European Union and so common in other countries outside (9). In this context, the antibiotic supplementation as an additive in most of the handling and preservative sperm extenders has been widely used in many species; in domestic ones such as ram (10), bull (11), stallion (12), or boar (13) and wild species: red deer (14) or brown bear (15). Many studies have demonstrated the beneficial effect of antibiotics inhibiting the bacterial proliferation in the sperm samples during their storage $(1,16-18)$. Most of these studies have been carried out in different species than ram, without species specific studies, which could generate unexpected effects on relevant production aspects such as fertility, prolificacy, fecundity, or sex-ratio. In the same way, most of these studies have been focused on the assessment of the effect of the antibiotics on the sperm quality assessed in vitro in buffalo, bull, and ram $(10,11,19)$. It is important to take into account that the use of sperm insemination doses with contamination could be related to deleterious effects on the female reproductive tract and estrus status $(20,21)$, reducing the embryonic survival, or even reducing the litter size (22) in swine. However, the effects of antibiotics in important productive parameters such as fertility, prolificity, fecundity, or sex-ratio have not been widely studied in ram, usually being extrapolations and copies from other species. To get a deep knowledge about the effects of antibiotics not only on the sperm quality but also in the future production of the sperm doses is very important to optimize protocols and to reduce the use of antibiotics since the antimicrobial resistance supposes a global and serious danger not only for the human or animal health but also for the economics (23).

This study aimed to go further and assess the effect of three different antibiotic treatments, which are the most extensively used, not only in the sperm quality or assessing the inhibitory effect on the bacterial growth but also assessing these important parameters of productivity such as fertility, multiple lambing frequency, prolificacy, fecundity, and sex-ratio, which have a very important impact on the ovine livestock.

\section{MATERIALS AND METHODS}

\section{Reagents and Media}

All the products used in this paper were of at least reagent grade and were acquired from Sigma Aldrich (Madrid, Spain) unless otherwise stated. The medium for cytometry assessment was PBS.

\section{Animals and Sperm Collection}

Sperm samples were collected from mature ram males during the breeding season. The ejaculates were collected by artificial vagina at $40^{\circ} \mathrm{C}$ (Minitüb, Tiefenbach, Germany), and the tubes were maintained at $35^{\circ} \mathrm{C}$ during the initial evaluation of sperm quality. The volume was calculated using the graduation marks of the collection tubes. Mass motility was assessed by microscopy (warming stage at $38^{\circ} \mathrm{C}, 40 \mathrm{x}$; score: $0-5$; Labophot-2, Nikon, Tokyo, Japan), and the sperm concentration was assessed using a Nucleocounter n-100 (DADOS MARCAETC). Only ejaculates with good quality (volume: $\geq 0.5 \mathrm{~mL}$; mass motility: $\geq 4$; sperm concentration $\geq 3,000 \times 10^{6} \mathrm{~mL}^{-1}$ ) were used and processed for the experiment.

\section{Experimental Design}

Before freezing, samples (1 valid ejaculate per male) were diluted down to a final concentration of $100 \times 10^{6}$ sperm $/ \mathrm{mL}$ in their respective extender (Tes-Tris-Fructose 20\% egg yolk_4\% glycerol_320mOsm/Kg) as follows: without antibiotics (Control), with Penicillin-Streptomycin (PS) to a final concentration of $500 \mathrm{UI}$ and $625 \mu \mathrm{g} / \mathrm{mL}$, respectively, Lincomycin-Spectinomycin (LS) to a final concentration of 300 and $600 \mu \mathrm{g} / \mathrm{mL}$, respectively, and Gentamicin $(\mathrm{G})$ to a final concentration of $1,000 \mu \mathrm{g} / \mathrm{mL}$. After this, samples were frozen and thawed as explained in point Sperm Cryopreservation. Samples were assessed in vitro just after thawing (T0) and after submitting them to a stress test of $2 \mathrm{~h}$ of incubation at $37^{\circ} \mathrm{C}$ (T2), except for the microbial assessment, which was carried out just after thawing (T0). For the in vivo trial (artificial insemination), samples were processed as described in statement Fertility Trials.

\section{Sperm Cryopreservation}

Sperm extended samples were cryopreserved following the protocol (24) modified by Alvarez et al. (25). Samples were refrigerated at $-0.25^{\circ} \mathrm{C} / \mathrm{min}$ from 30 to $5^{\circ} \mathrm{C}$ in the refrigerated chamber. After $2 \mathrm{~h}$ of equilibration at $5^{\circ} \mathrm{C}$, samples were packed in $0.25 \mathrm{ml}$ straws and then frozen in a programmable biofreezer (Kryo 10 Series III; Planer PLC, Sunbury-on-Thames, UK) at $-20^{\circ} \mathrm{C} / \mathrm{min}$ up to $-100^{\circ} \mathrm{C}$, transferred to liquid nitrogen containers, and stored for a minimum of 1 month. Thawing was performed by dropping straws in the water at $65^{\circ} \mathrm{C}$ for $6 \mathrm{~s}$. One part of the samples was used to carry out the artificial inseminations; another part of the straws was used to carry out sperm in vitro assessment, just after thawing (T0) and after $2 \mathrm{~h}$ of incubation at $37^{\circ} \mathrm{C}$ as a stress test (T2). The last part of the samples was used to perform the microbial culture. 


\section{In vitro Sperm Evaluation}

Straws from 9 males (one ejaculate per male) were used for the in vitro assessment as follows.

\section{Computer-Assisted Sperm Analysis}

Samples were diluted to $30 \times 10^{6}$ sperm $/ \mathrm{mL}$ in their freezing extender to check the motility. A warmed Makler counting chamber was loaded with $5 \mu \mathrm{L}$ of the sample. The analysis was carried out using a CASA system (Computer Assisted Sperm Analysis), consisting of an optical phase-contrast microscope (Nikon Labophot-2) (fitted with negative phasecontrast objectives and a warming stage at $37^{\circ} \mathrm{C}$ ), a Basler A312fc camera (Basler, Germany), and a PC with the sperm Class Analyser software (ISAS v. 1.2; Proiser, Valencia, Spain). The magnification was $100 \times$. At least five fields per sample were acquired at an acquisition rate of 25 images per second, recording a total of 200 motile sperm. The following parameters were used for the study: total motility (\%; TM), progressive motility (\%; PM), average path velocity ( $\mu \mathrm{m} / \mathrm{sec}$; VAP) straightline (rectilinear) velocity ( $\mu \mathrm{m} / \mathrm{s}$; VSL), and amplitude of lateral head displacement ( $\mu \mathrm{m} ; \mathrm{AHL})$.

Image sequences were saved and analyzed afterward using the editing facilities provided by ISAS. Sperm were considered motile when VCL $>10 \mu \mathrm{m} / \mathrm{s}$ and progressive if VCL $>10$ and straightness (STR) $>80 \%$. The progressive sperm subpopulations were classified according to velocities as follows: Slow (VCL $<25)$, Medium (VCL > 25 and $<65$ ), and Rapid (VCL >65). Other events different from spermatozoa were removed, and settings were adjusted in each case to assure a correct track analysis.

\section{Flow Cytometry}

Flow cytometry acquisition was performed in a flow cytometer (MACSQuant Analyser 10, Miltenyi Biotech, Madrid, Spain) equipped with three lasers emitting at 405, 488, and $635 \mathrm{~nm}$ and 10 photomultiplier tubes (PMTs): V1 (excitation $405 \mathrm{~nm}$, emission 450/50 nm), V2 (excitation $405 \mathrm{~nm}$, emission $525 / 50 \mathrm{~nm}$ ), B1 (excitation $488 \mathrm{~nm}$, emission 525/50 nm), B2 (excitation $488 \mathrm{~nm}$, emission 585/40 nm), B3 (excitation $488 \mathrm{~nm}$, emission 655-730 nm; 655LP + split 730), B4 (excitation $499 \mathrm{~nm}$, emission 750 LP), R1 (excitation $635 \mathrm{~nm}$, emission $655-730 \mathrm{~nm}$; $655 \mathrm{LP}+$ split 730), and R2 (excitation $635 \mathrm{~nm}$, emission filter 750 LP). The system was controlled using MACS Quantify software (Miltenyi Biotech, Madrid, Spain). These excitation and emission wavelengths allowed us to find probe combinations that can simultaneously assess multiple parameters in a large number of sperm (a total of 40,000 events per sample and at least 20,000 sperm cells, at a flow rate of 200-300 cells per second, were acquired). Data were analyzed using FlowJo v.10.2 (Ashland, USA).

\section{Simultaneous Flow Cytometric Assessment of the Viability, Caspase 3 and 7 Activity, and Metabolic Activity (ROS Generation)}

Sperm samples of different experimental groups were diluted in PBS medium to obtain a total of $2 \times 10^{6}$ of sperm per sample; these samples were washed and centrifuged at $500 \mathrm{~g}$ for $10 \mathrm{~min}$ at room temperature (RT). Lyophilized Zombie Violet ${ }^{\mathrm{TM}}$
(Biolegend, San Diego, California, EEUU) dye was reconstituted in DMSO following the manufacturer's instructions (100 $\mu \mathrm{l}$ of DMSO to one vial of Zombie Violet ${ }^{\mathrm{TM}}$ dye). CellEvent ${ }^{\mathrm{TM}}$ Caspase-3/7 and CellROX ${ }^{\mathrm{TM}}$ Deep Red (Invitrogen, Eugene, Oregon, EEUU) were purchased as a $2 \mathrm{mM}$ and $2.5 \mathrm{mM}$ stabilized solution, respectively. Stock solutions of fluorescence probes were prepared at $1 \mu \mathrm{L}$ and kept at $-20^{\circ} \mathrm{C}$ in the dark until needed.

Zombie Violet ${ }^{\mathrm{TM}}$ stock solutions were resuspended in $1 \mathrm{~mL}$ of PBS while CellEvent ${ }^{\mathrm{TM}}$ Caspase-3/7 and CellROX ${ }^{\mathrm{TM}}$ in $10 \mu \mathrm{L}$. After samples centrifugation, the supernatant was discarded, and the sperm pellet was incubated at RT for $30 \mathrm{~min}$ in the dark with $96 \mu \mathrm{L}$ of Zombie Violet ${ }^{\mathrm{TM}}$ (membrane integrity probe) $(1: 1,000$ final dilution), $2 \mu \mathrm{L}$ of CellEvent ${ }^{\mathrm{TM}}$ Caspase-3/7 (apoptosis marker) $4 \mu \mathrm{M}$ final concentration, and $2 \mu \mathrm{L}$ of CellROX ${ }^{\circledR}$ (ROS content labeling) $5 \mu \mathrm{M}$ final concentration. After that, another washing step was performed to stop cell staining, and the pellet was resuspended in $1 \mathrm{~mL}$ of PBS, carrying out the analysis immediately by flow cytometry.

The interest sperm subpopulations assessed were plotted as follows: Non-Apoptotic Viable Sperm (Zombie low intensity, Caspase $3 \& 7$ negative), Apoptotic Sperm (Zombie low intensity -alive-, Caspase $3 \& 7$ positive), and High Metabolically Active Sperm (Zombie low intensity, CellROX positive).

\section{Bacteriological Assessment}

Straws from 8 males for each treatment, without antibiotics (control), with Penicillin-Streptomycin, with LincomycinSpectinomycin, or with Gentamicin, were thawed and $150 \mu \mathrm{L}$ of each sample were plated onto blood agar plates (Oxoid, Wesel, Germany). The inoculum was spread rapidly over the entire agar surface with a sterile Digralsky spreader. Plates were incubated at $37^{\circ} \mathrm{C}$ under aerobic conditions and inspected after $48 \mathrm{~h}$ incubation. Bacterial growth was expressed as colony-forming units CFU/mL. Subcultures were performed until pure cultures were obtained. Primary identification was based on Gram staining and catalase and oxidase tests while confirmation was carried out using matrix-assisted laser desorption ionization time-of-flight mass spectrometry (MALDI-TOF MS, Bruker, Madrid, Spain).

\section{Fertility Trials}

For the fertility trial, sperm doses $\left(25 \times 10^{6}\right.$ sperm/straw $)$, frozenthawed as above described (2.4), from 10 mature males (Churra breed) were used. The experimental samples were randomly and sequentially distributed through 7 commercial farms following a commercial artificial insemination program (Churra breed improvement program) under the strict supervision of our research group. Adult Churra ewes (852 females between 2 and 5 years old lambed previously) were subjected to treatment for estrous induction and synchronization using intravaginal sponges with $20 \mathrm{mg}$ fluorogestone acetate (Chronogest ${ }^{\circledR}$, MSD) over 14 days. The sponges were removed and 500 IU of eCG were injected -IM- Folligon $^{\circledR}$, MSD). Laparoscopic inseminations were performed by two vets with extensive experience, between 64 and $67 \mathrm{~h}$ after the removal of the sponges. The animals, having fasted for the previous $24 \mathrm{~h}$, were tied to a special 
cradle (IMV), placed on an inclined plane $\left(45^{\circ}\right)$, and the area in front of the teat was shaved and cleaned. Local anesthesia (mepivacaine HCL 2\%, Braun ${ }^{\mathrm{TM}}$ ) was applied to the puncture points. Then two portals (for vision and manipulation/injection) were inserted by performing a pneumoperitoneum $\left(\mathrm{CO}_{2}\right)$. The semen, placed in a special applicator (Transcap ${ }^{\circledR}$, IMV), was injected under visual inspection into each uterine horn $(0.12 \mathrm{~mL}$, $\left.12.5 \times 10^{6} \mathrm{spz}\right)$. Fertility [(lambing ewes/inseminated ewes) $\times 100$ ] was calculated according to the births registered at 137-154 days post-insemination. Moreover, viable offspring and sex were registered, and prolificacy (lambs/lambed ewes), multiple lambing frequency $[$ (multiple lambing/total lambing) $\times$ 100], fecundity (lambs/inseminated ewes) and sex-ratio [(female lambs/total lambs) $\times 100$ ] were calculated.

\section{Statistical Analysis}

For the in vitro quality, data were analyzed using the SAS ${ }^{\mathrm{TM}}$ V.9.1 Package (SAS Institute Inc., Cary, NC, USA). Results are shown as means and standard errors of the mean. The normality of data was verified by Kolmogorov-Smirnov tests. Analyses of the data were carried out using linear mixed-effects models (MIXED procedure, ML method), including the type of antibiotic (C, PS, LS, and G) and incubation time after thawing ( 0 vs. $2 \mathrm{~h}$ ) as fixed factors, and males as a random effect. Significant fixed effects were further analyzed using multiplecomparisons of means with Tukey contrasts. A significance level of $P<0.05$ was used; $P<$ 0.1 was considered as a trend.

Fertility, multiple lambing frequency, and sex ratio data were compared using a GENMOD procedure considering a binary response model. The statistical model included the type of antibiotic (C, PS, LS, and G) as a factor, and fertility, multiple lambing frequency, and sex-ratio as a response variable. Betweengroup differences in the frequency were tested using Wald ChiSquare. For sex-ratio, the study was completed comparing each experimental group to the "expected value" (50:50). Prolificacy and fecundity data were compared using a GLM procedure using the type of antibiotic as a factor; between-group differences were tested by Duncan test. The significance level was set at $P<0.05$.

\section{RESULTS}

\section{Sperm Motility}

The mean, standard error, and male distribution for several sperm motility parameters are showed in Figure 1. Just after thawing non-significant differences $(P>0.05)$ were observed either for TM or for PM among the different antibiotic treatments (Figures 1A,B). After $2 \mathrm{~h}$ of incubation at $37^{\circ} \mathrm{C}$, all the samples showed a significant decrease from $0 \mathrm{~h}$, but no difference was observed between treatments. In contrast, when assessing the rapid $\mathrm{PM}, \mathrm{G}$ samples showed significantly lower values $(P<$ 0.05) than $C$ just after thawing (Figure 1C). In the same way, when assessing ALH and VSL G samples showed significantly lower values $(P<0.05)$ than the $\mathrm{C}$ samples not only just after thawing but also after $2 \mathrm{~h}$ of incubation at $37^{\circ} \mathrm{C}$ (Figures 1D,E). Also, samples treated with PS showed significantly lower values of ALH than the C samples after submitting the samples to the incubation. Similarly, those samples treated with LS exhibited lower values $(P<0.05)$ of VSL respect to the control just after thawing. Finally, just after thawing, PS and G had significantly lower values of VAP $(P<0.05)$ than the $C$ (Figure 1F). After the incubation, these significant differences disappeared.

\section{Membrane Integrity (Sperm Viability), Caspase 3 and 7 Activity, and Metabolic Activity}

The mean, standard error, and male distribution of the different evaluated sperm parameters are shown in Figure 2. No significant differences were found when assessing the viability just after thawing between the control and each treatment (Figure 2A). The viability of all groups was significantly lower $(P<0.05)$ after $2 \mathrm{~h}$ of incubation. After this incubation, PS kept higher values of non-apoptotic viable sperm than $\mathrm{C}(P$ $<0.05)$. Assessing the percentage of apoptotic cells, there were no significant differences among treatments either after thawing (T0) or after the incubation (T2) with respect to the C (Figure 2B). Finally, after assessing the metabolic status of sperm mitochondria via ROS generation, data indicated a higher tendency value $(P<0.06)$ in PS than the Control, not raising the significance, just after thawing. All treatments had a significant decrease $(P<0.05)$ after $2 \mathrm{~h}$ of incubation. However, PS showed significantly higher values of metabolic activity than the $\mathrm{C}$ after $2 \mathrm{~h}$ of incubation $(P<0.05)$. In contrast, LS and $\mathrm{G}$ did not show any significant differences $(P>0.05)$ compared to $C$ (Figure 2C) for this parameter.

\section{Bacteriological Assessment}

The mean and standard error of the mean of $\mathrm{CFU} / \mathrm{mL}$ recovered for each treatment is shown in Figure 3. A significant reduction in the number of viable bacteria after $G$ and LS treatments as compared with the $\mathrm{C}$ without antibiotics was recorded $(P<0.05)$. PS treatment also decreases bacterial concentration although differences do not reach statistical significance when compared with control ( $P=0.345$; Figure 3).

Most of the samples resulted in the growth of a mixed microorganism population with up to 16 different species. The highest number of different bacterial species was identified in the C group without antibiotics, followed by PS, LS, and finally G with the lowest number of different bacterial species (Figure 4). A total of 10 genera and 16 bacterial species (Figure 4) were identified with Pseudomonas (3 isolates) and Staphylococcus (3 isolates) as the most common genera followed by E. coli. In this sense, $G$ was the treatment with the highest antimicrobial spectra (4 survivor species) followed by LS (8 survivor species) and PS (10 survivor species) (Figure 4).

\section{Fertility Trials}

Samples treated with PS, the standard treatment, showed fertility of $52.0 \%$. In the same way, samples treated with LS (50.5\%) and C $(52.9 \%)$ showed similar results $(P>0.05)$. In contrast, those samples treated with $\mathrm{G}$ exhibited the worst results (38.8\%) being significantly lower $(P<0.05)$ than the other treatments (Table 1$)$.

Similar prolificacy results were observed between $C, G$, and LS $(P>0.05)$, while PS $(1.67 \pm 0.07)$ showed significantly higher results $(P<0.05)$ than LS. Multiple lambing frequency followed 
A

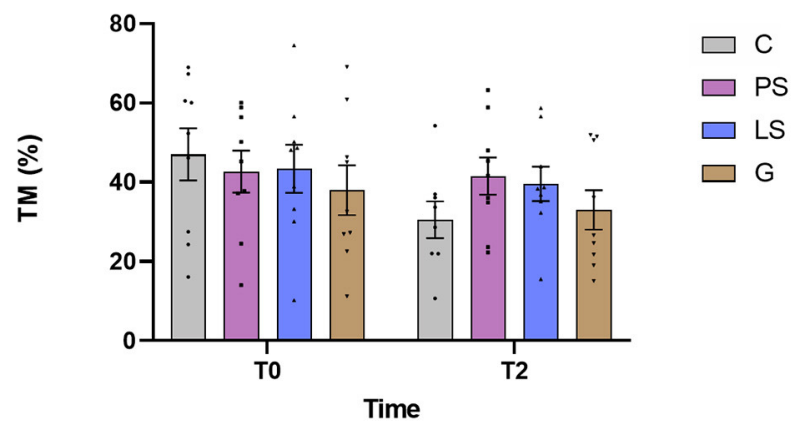

C

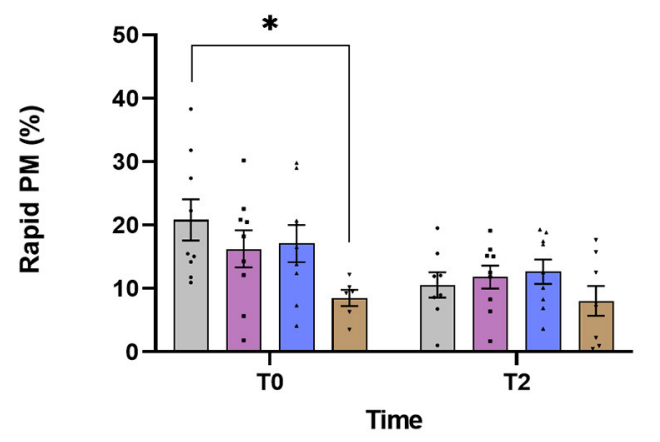

E

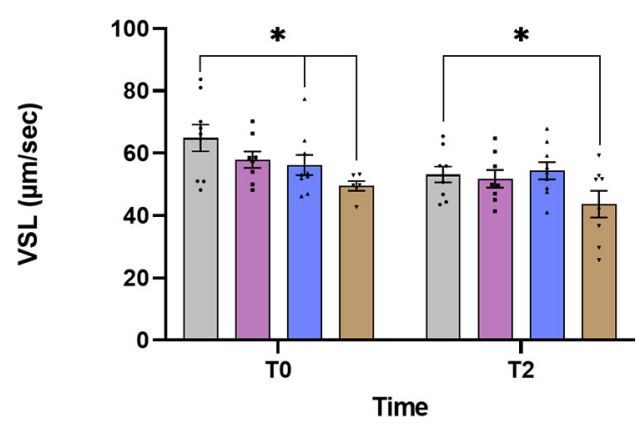

B

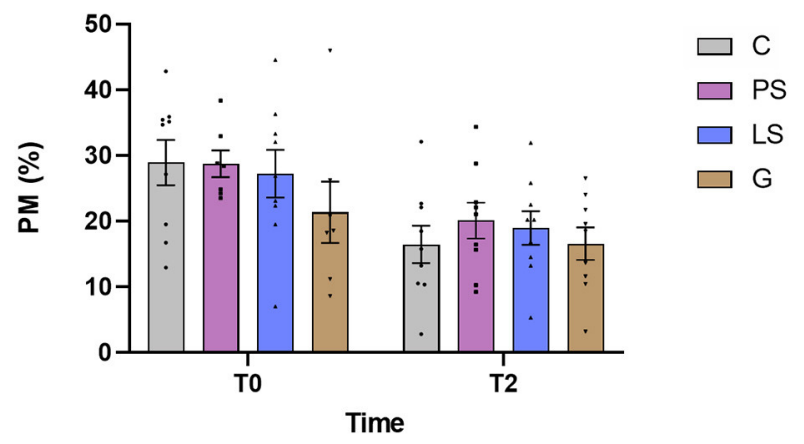

D

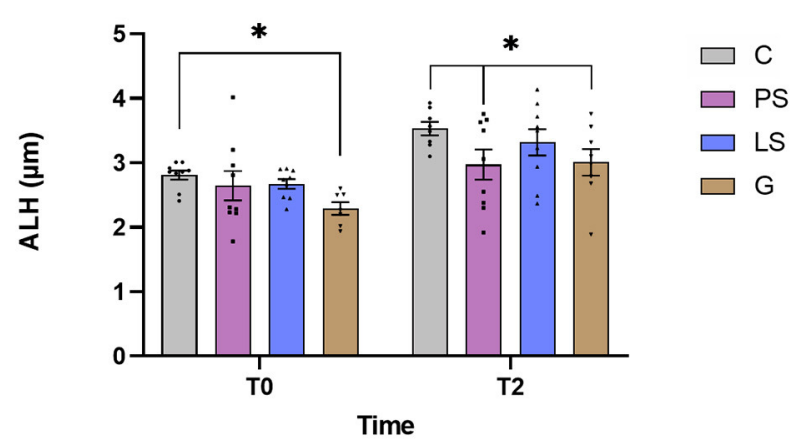

$\mathbf{F}$

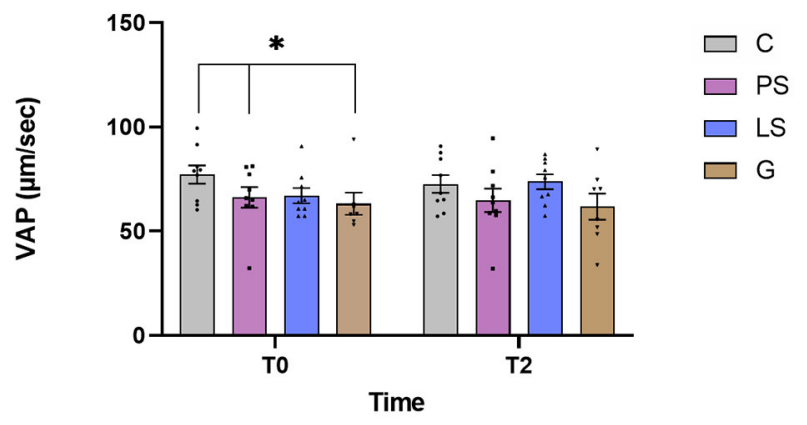

FIGURE 1 | Ram sperm motility data in the four experimental groups by time (just after thawing -TO- and after $2 \mathrm{~h}$ of incubation at $37^{\circ} \mathrm{C}-\mathrm{T} 2-$-): Control (C), without antibiotics; Penicillin-Streptomycin (PS); (500 UI)-625 $\mu \mathrm{g} / \mathrm{mL}$, respectively; Lincomycin-Spectinomycin (LS); 300-600 $\mu \mathrm{g} / \mathrm{mL}$ respectively; and Gentamicin (G) 1,000 $\mathrm{g} / \mathrm{mL}$. (A) Total motility (TM, \%); (B) progressive motility (PM, \%); (C) rapid progressive motile sperm (Rapid PM, \%), (D) amplitude of the lateral head movement (ALH, $\mu \mathrm{m}),(\mathbf{E})$ velocity according to the straight path $(\mathrm{VSL}, \mu \mathrm{m} / \mathrm{s})$, and (F) velocity according to the smoothed path (VAP, $\mu \mathrm{m} / \mathrm{s})$. Nine males were analyzed (1 ejaculate per male) including the same males in each experimental group. Graph dots represent individual male ejaculate. Significant differences $(P<0.05)$ are represented with an asterisk between the antibiotic treatment and the Control sample without antibiotics.

exactly the same significance distribution among treatments as prolificacy (Table 2). The results obtained in fecundity showed one more time the lowest rate in those samples assessed with G $(0.59 \pm 0.06)$, being significantly lower $(P<0.05)$ than the $C$ and PS $(0.81 \pm 0.06$ and $0.83 \pm 0.07$, respectively). For its part, samples treated with LS $(0.74 \pm 0.06)$ did not show significant differences with respect to the other treatments (Table 2).
There was no significant sex ratio distortion $(P>0.05)$ with the expected value (50:50) in each experimental group. The $C$ obtained $54.7 \%$ of females, being the treatment with the highest deviation of sex-ratio to females $(P<0.05)$. On the opposite, the percentage of females at birth was lower $(P<0.05)$ for those samples treated with G $(42.4 \%)$ and LS $(38.4 \%)$ than C (Figure 5). The result obtained for the samples treated with PS 

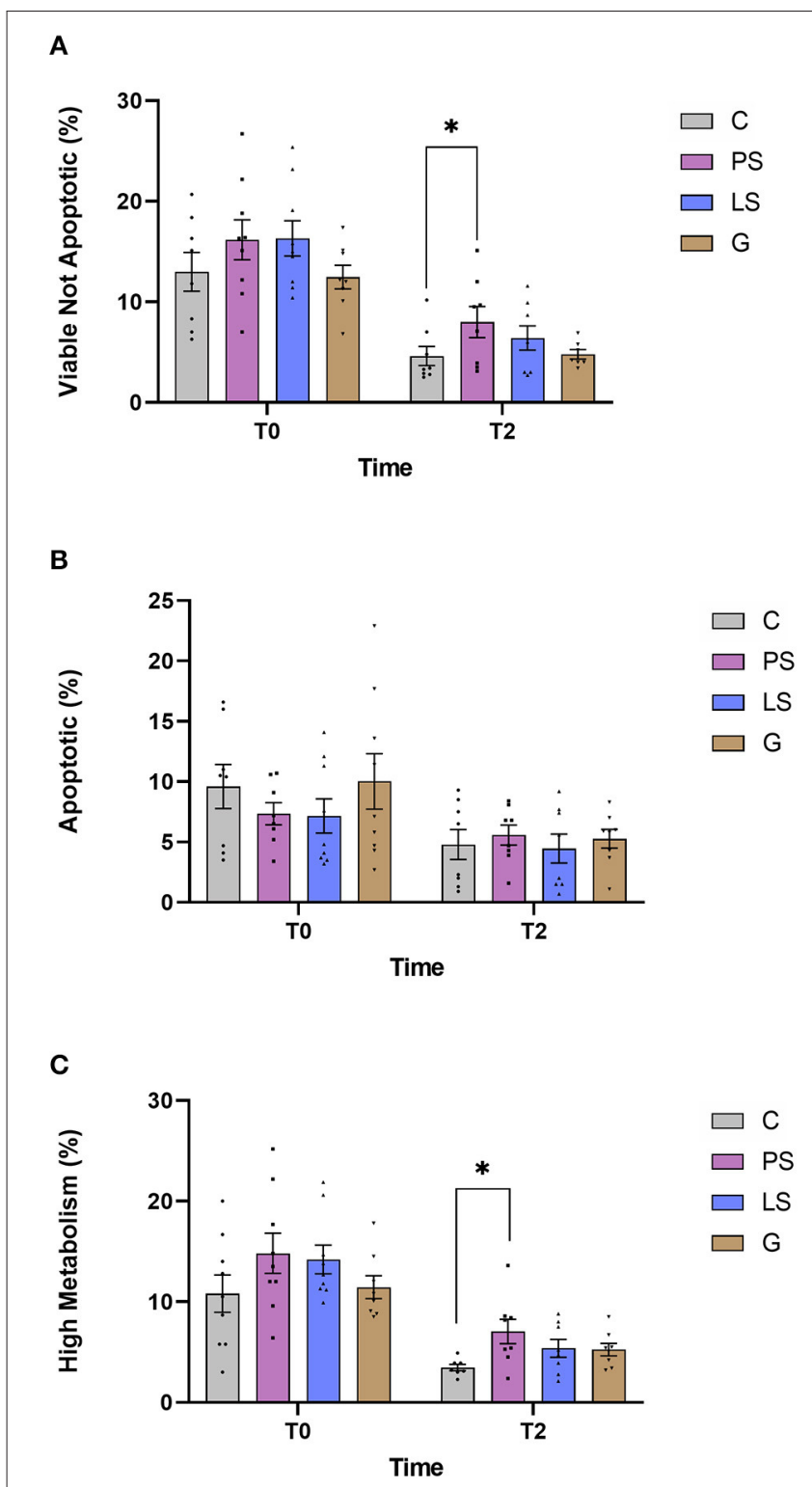

FIGURE 2 | Ram sperm multiparametric flow cytometry data in the four experimental groups by time (just after thawing -T0- and after $2 \mathrm{~h}$ of incubation at $37^{\circ} \mathrm{C}$-T2-): Control (C), without antibiotics; Penicillin-Streptomycin (PS); (500 UI)-625 $\mu \mathrm{g} / \mathrm{mL}$, respectively; Lincomycin-Spectinomycin (LS); 300-600 $\mu \mathrm{g} / \mathrm{mL}$, respectively; and Gentamicin (G) 1,000 $\mu \mathrm{g} / \mathrm{mL}$. (A) Zombie low intensity cells and Caspase $3 \& 7$ negative cells (viable not apoptotic sperm, $\%)$; (B) Zombie low intensity cells and Caspase 3/7 positive cells (apoptosis, $\%)$; (C) Zombie low intensity cells and CellROX-positive cells (Sperm with high metabolic activity, \%). Nine males were analyzed (1 ejaculate per male) including the same males in each experimental group. Graph dots represent individual male ejaculate. Significant differences $(P<0.05)$ are represented with an asterisk between the antibiotic treatment and the Control sample without antibiotics.

was the closest to a expected proportion of $50 \%$ (48.4\% females) and not being significantly different $(P>0.05)$ than the other 3 treatments (Figure 5).

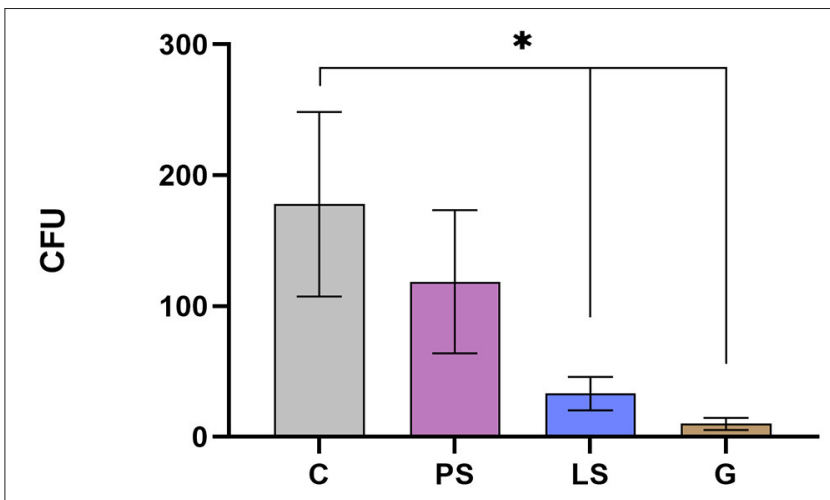

FIGURE 3 | Total viable aerobic bacterial (colony-forming units) in the four experimental groups: Control (C), without antibiotics; Penicillin-Streptomycin (PS); (500 UI)-625 $\mu \mathrm{g} / \mathrm{mL}$, respectively; Lincomycin-Spectinomycin (LS) 300-600 $\mu \mathrm{g} / \mathrm{mL}$, respectively; and Gentamicin (G) 1,000 $\mu \mathrm{g} / \mathrm{mL}$. Eight males were analyzed (1 ejaculate per male) including the same males in each experimental group. Significant differences $(P<0.05)$ are represented with an asterisk between the antibiotic treatment and the Control sample without antibiotics.

\section{DISCUSSION}

The increasing challenge to health care attributable to antimicrobial resistance, and the subsequent absence of access to effective treatments, is a worldwide concern. In the same way, the use of antibiotics as an additive in sperm extender is a standard nowadays. Semen is normally colonized by a high variety of microorganisms that may reduce sperm quality. However, contradictory results on the effect of bacterial flora can be found, as well as in the effect of different antibiotic families depending on such important factors as the species, the sperm extender composition, or even the cryopreservation protocols (26). In this context, it is important to carry out an intensive assessment, not only assessing in vitro sperm parameters but also assessing important productive parameters, of the main antibiotic families used nowadays in sperm extenders and get a clear idea about their effect and the suitability of their use. In this study, a total of 10 genera and 16 bacterial species were identified with Pseudomonas and Staphylococcus as the most common genera followed by E. coli. Other bacterial species were also isolated in a lower number such as Sphingomonas paucimobilis, Deftia acidovorans, Mycrobacterium oxydans, Kocuria, and Corynebacterium. Some of these bacteria were also found by Yániz et al. (10) in ram sperm. In the same way, E.coli, which is one of the most common species isolated in the current experiment, has also been detected as the most frequent bacterial species in human (6), equine (18), canine (27), and porcine (20) sperm doses.

As we have previously described, the effect of antibiotics on sperm quality have controversial results attending to factors such as species, type of extender, or cryopreservation protocol. Many authors recommended some antibiotics such as gentamicin as a suitable additive for semen storage $(18,28,29)$. In the present study, gentamicin was the antibiotic exhibiting the most 


\section{Qualitative description of bacterial species isolated in each treatment}

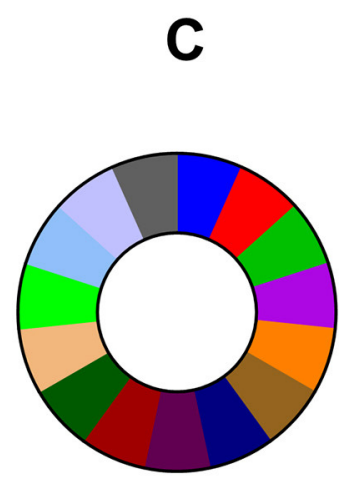

Total=15

- Corynebacterium cystidis $\square$ Corynebacterium renale $\square$ Escherichia coli

$\square$ Globicatella sanguinis

$\square$ Kocuria rhizophila

$\square$ Mycrobacterium oxydans

- Pseudomonas koreensis

口 Pseudomonas spp

$\square$ Pseudomonas veronii

- Sphingomonas paucimobilis

$\square$ Staphylococcus cohnii ssp

$\square$ Staphylococcus equorum

$\square$ Staphylococcus warneri

$\square$ Stenotrophomonas rhizolipa

$\square$ Streptococcus pluranimalium

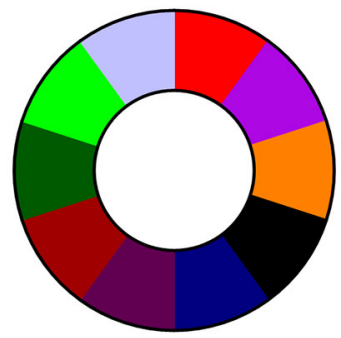

$\square$ Corynebacterium renale

$\square$ Globicatella sanguinis

$\square$ Kocuria rhizophila

- Mycrobacterium liquefaciens

- Pseudomonas koreensis

च Pseudomonas spp

口 Pseudomonas veronii

Sphingomonas paucimobilis

$\square$ Staphylococcus equorum

Stenotrophomonas rhizolipa

Total $=10$

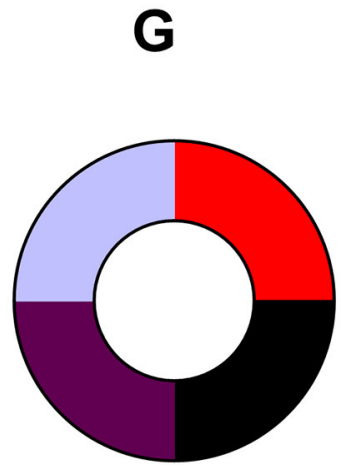

$\square$ Corynebacterium renale

- Mycrobacterium liquefaciens

- Pseudomonas spp

$\square$ Stenotrophomonas rhizolipa

Total $=8$

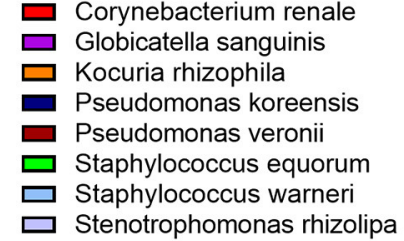

Total $=4$

FIGURE 4 | Bacterial species isolated in each treatment after thawing: Control (C), without antibiotics; Penicillin-Streptomycin (PS), (500 UI)-625 $\mu \mathrm{g} / \mathrm{mL}$, respectively; Lincomycin-Spectinomycin (LS), 300-600 $\mu \mathrm{g} / \mathrm{mL}$, respectively; and Gentamicin (G) 1,000 $\mu \mathrm{g} / \mathrm{mL}$. Eight males were analyzed (1 ejaculate per male) including the same males in each experimental group.

powerful effect inhibiting bacterial growth together with LS. In contrast, Gentamicin was also the treatment with a lower sperm quality assessed in vitro. Jasko et al. (29) showed a negative effect on sperm motility when using gentamicin concentrations $>1$ $\mathrm{mg} / \mathrm{mL}$ in equine sperm. On the contrary, Yániz et al. (10) found that the concentration of gentamicin in sperm extender up to 0.5 $\mathrm{g} / \mathrm{l}$ did not affect sperm motility and viability after storage at $15^{\circ} \mathrm{C}$ for $48 \mathrm{~h}$ in ram. At this point, $1 \mathrm{~g} / \mathrm{L}$ of gentamicin concentration looked like the safety limit for this type of antibiotic in equine. However, our results report a significant decrease in fertility and fecundity when this concentration of gentamicin was used. It could be possible that ram sperm are more sensitive to this type of antibiotic at this concentration than stallion. It should be taken into account that our study is the first time that a negative effect on fertility has been described in ram when gentamicin is used as an additive extender. With the same concentration (1 g/L) of Gentamicin, Aurich and Spergser (1) showed that sperm motility assessed in vitro was significantly reduced and the bacterial inhibition was not as high as expected in stallion sperm. This fact shows that there is a very important specie specific factor that can determine the efficiency of antibiotical substances in sperm extender among species. In this way, and after assessing our results, we can conclude that our concentration of gentamicin works greatly inhibiting the bacterial growth, but it resulted in a 
TABLE 1 | Fertility results (lambed ewe/100 inseminated ewe) by treatment as follows: Control (without antibiotics), Penicillin-Streptomycin; with Penicillin (500 UI) and Streptomycin to a final concentration of $625 \mu \mathrm{g} / \mathrm{mL}$; Lincomycin-Spectinomycin to a final concentration of 300 and $600 \mu \mathrm{g} / \mathrm{mL}$, respectively; and Gentamicin to a final concentration of $1,000 \mu \mathrm{g} / \mathrm{mL}$.

\begin{tabular}{lccc}
\hline Treatment & $\begin{array}{c}\text { Inseminated } \\
\text { ewes (n) }\end{array}$ & $\begin{array}{c}\text { Lambed } \\
\text { ewes (n) }\end{array}$ & Fertility (\%) \\
\hline $\begin{array}{l}\text { Control } \\
\text { (without antibiotics) }\end{array}$ & 221 & 117 & $52.9 \mathrm{a}$ \\
$\begin{array}{l}\text { Penicillin-Streptomycin } \\
(500 \mathrm{Ul}-625 \mu \mathrm{g} / \mathrm{mL})\end{array}$ & 211 & 105 & $49.7 \mathrm{a}$ \\
$\begin{array}{l}\text { Lincomycin-Spectinomycin } \\
(300 \text { and } 600 \mu \mathrm{g} / \mathrm{mL})\end{array}$ & 206 & 104 & $50.5 \mathrm{a}$ \\
$\begin{array}{l}\text { Gentamicin } \\
(1,000 \mu \mathrm{g} / \mathrm{mL})\end{array}$ & 214 & 83 & $38.8 \mathrm{~b}$ \\
\hline
\end{tabular}

Ten males were used.

Different low case letters $(a, b)$ indicate significant differences $(P<0.05)$ among treatments.

toxic effect on some sperm quality assesments (rapid progressive motility and different kinetic parameters: VAP, VSL, and ALH, Figure 2). This altered sperm quality could be affecting negatively important livestock parameters such as fertility. This fact is correlated to the decreased progressive motility assessed in vitro. In this context, high values of progressive motile sperm have been demonstrated as a good correlation factor with fertility in humans $(30,31)$. Probably this negative effect is due to some deleterious effects at the structural level since the sperm metabolism was not affected by the gentamicin respect to the C samples. A recent study carried out by Riesco et al. (32) demonstrated a novel sperm protein (ProAKAP4) as a promising diagnostic parameter of sperm quality in ram sperm, so long correlated to sperm motility. This protein is the most expressed protein of the sperm fibrous sheath being an important part of the flagellum $(33,34)$. This type of protein has also been related to sperm quality in several species such as humans (35), mice (36), or boar (37). In this sense, further investigations should be carried out to identify the exact mechanism of gentamicin toxicity. In any case, and in view of the results obtained in the present study, it is clear that gentamicin is not a suitable option, under these conditions, taking into account their negative effects, especially in the productive parameters.

The PS was the treatment with lower efficacy inhibiting bacterial growth. It gets a lower number of CFU but this decrease was not significant with respect to the control samples. This treatment (PS) has been one of the most common and extended antibiotics since it was discovered in 1928, so this intensive use for many decades could have produced a mechanism of resistance to this type of treatment $(38,39)$. In contrast, when the sperm samples were assessed in vitro those samples treated with PS showed the best results in the sperm physiology keeping higher values of viable sperm after submitting thawed samples to a stress test. The same effect was found when assessing the sperm with high mitochondrial activity, getting the best result of the experiment at both times 0 and $2 \mathrm{~h}$. This fact could suggest that
TABLE 2 | Multiple lambing frequency (\%), prolificacy (lambs/lambed ewe), and fecundity results (lambs/inseminated ewes) by treatment as follows: Control (without antibiotics), Penicillin-Streptomycin; with Penicillin (500 UI) and Streptomycin to a final concentration of $625 \mu \mathrm{g} / \mathrm{mL}$; Lincomycin-Spectinomycin to a final concentration of 300 and $600 \mu \mathrm{g} / \mathrm{mL}$, respectively; and Gentamicin to a final concentration of $1,000 \mu \mathrm{g} / \mathrm{mL}$.

\begin{tabular}{|c|c|c|c|}
\hline Treatment & $\begin{array}{l}\text { Multiple lambing } \\
\text { frec. (\%) }\end{array}$ & $\begin{array}{l}\text { Prolificacy } \\
\text { (MEAN } \pm \text { SE) }\end{array}$ & $\begin{array}{l}\text { Fecundity } \\
(\mathrm{MEAN} \pm \mathrm{SE})\end{array}$ \\
\hline $\begin{array}{l}\text { Control } \\
\text { (without antibiotics) }\end{array}$ & 48.72ab & $1.52 \pm 0.05 a b$ & $0.81 \pm 0.06 a$ \\
\hline $\begin{array}{l}\text { Penicillin-Streptomycin } \\
\text { (500 UI-625 } \mu \mathrm{g} / \mathrm{mL} \text { ) }\end{array}$ & $55.24 a$ & $1.67 \pm 0.07 a$ & $0.83 \pm 0.07 a$ \\
\hline $\begin{array}{l}\text { Lincomycin-Spectinomycin } \\
\text { (300 and } 600 \mu \mathrm{g} / \mathrm{mL} \text { ) }\end{array}$ & $41.35 b$ & $1.47 \pm 0.06 b$ & $0.74 \pm 0.06 a b$ \\
\hline $\begin{array}{l}\text { Gentamicin } \\
(1,000 \mu \mathrm{g} / \mathrm{mL})\end{array}$ & 45.78ab & $1.53 \pm 0.07 a b$ & $0.59 \pm 0.06 b$ \\
\hline
\end{tabular}

Ten males were used.

Different low case letters $(a, b)$ indicate significant differences $(P<0.05)$ among treatments.

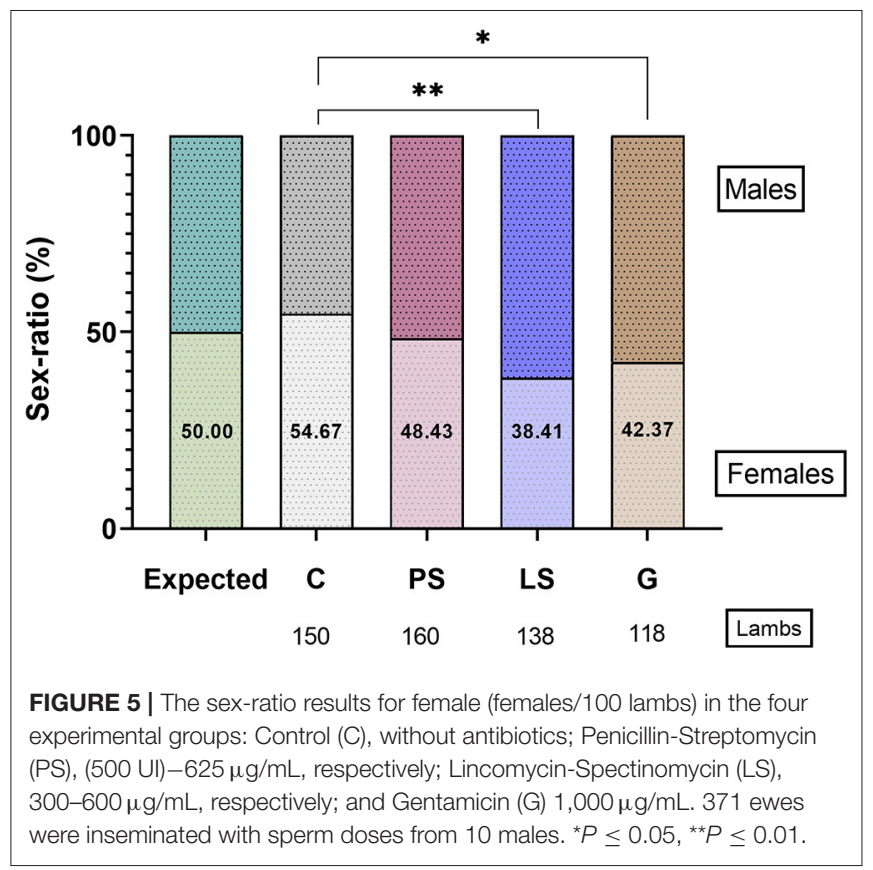

PS at this concentration is a suitable treatment since it inhibits in part the bacterial growth, not affecting the sperm quality. In the same way and after the field trials, PS keeps exhibiting similar results to Controls samples in fertility and prolificacy, not showing any adverse or toxic effect as the $G$ in the fertility, or the LS in the prolificacy.

Finally, the LS treatment exhibited very interesting and complex results. After assessing sperm quality in vitro, LS did not show any deleterious effect either in the sperm physiology or in the sperm motility respect to the $\mathrm{C}$ samples. In addition, it was after the $G$, the treatment with the highest bacterial inhibitory activity, but not exhibiting adverse effects on the sperm quality in vitro. This fact could suggest that this treatment (LS) at this concentration has a perfect balance between the 
bacterial inhibitory effects, not affecting the sperm physiology in ram. In this study, similar results to Azawi and Ismaeel (16), when assessing sperm quality in vitro, were obtained but opposite results when assessing the effect inhibiting bacterial growth, finding these authors a poor antimicrobial effect using a concentration of $1 \mathrm{mg} / \mathrm{ml}$ of lincomycin in ram. These differences could be due to several factors such as the use of Lincomicyn alone (not combined with spectinomycin) or the experimental design (refrigerated samples at $5^{\circ} \mathrm{C}$ till $96 \mathrm{~h}$ ). In any case, Lincomicyn seems to be more efficient when using combined with spectinomycin, allowing us to use lower concentrations, getting similar results in the sperm quality in vitro, and performing a very high inhibition in the bacterial growth. In the same way, Akhter et al. (19) have demonstrated the superiority of LS compared to PS combinations inhibiting bacterial growth in buffalo sperm samples. These and our results are in concordance with those obtained by Aleem et al. (40) in buffalo, where those authors agree that several bacterial species exhibited antimicrobial resistance to PS combinations while LS and others showed a higher antimicrobial effect. After the field trials, some interesting effects were observed. Neither fertility nor prolificacy or fecundity were affected as expected. However, after assessing the prolificacy we can observe that this parameter was lower in respect to the samples without antibiotic. This effect could be due to some kind of sublethal effect, not being capable to detect it in vitro as previously occurred in species such as boar (41) or buffalo (19). On the other hand, when the fecundity was assessed this lower prolificacy was compensated because the fecundity is a complex parameter where fertility and prolificacy are combined. This is the first time that these antibiotic treatments have been tested under field conditions in ram with a large number of ewes inseminated.

It is known that the plasma membrane from X or Y-sperm are diferent. Korchunjit et al. (42) found that different defined combinations of cryomedia and sperm extender significantly alter the survivar ratio of frozen-thawed $\mathrm{X}-\mathrm{Y}$ sperm. In this sense, some interesting results were observed in our study when the sex ratio was assessed. Samples without antibiotics have deviated to females but LS and G had deviated to males. Neither the experimental group nor the control group has differences concerning the expected sex ratio (50:50). If we observed the results obtained in CFU and sex ratio we can observe that sperm samples with higher microbial charge result in a higher number of females, and the treatments with the lower microbial contamination (LS and G) resulted in a significantly lower number of females, which is negative in dairy species where females have the main economical value. At this point, it looks like X-sperm has some kind of resistance to microbial contamination, or that the Y-sperm are more resistant to some possible deleterious or toxic effect of LS and G. To this concern, these results pave the way for further investigations about the interaction bacteria/sperm, and to assess the different effect of antibiotic treatments in the different sperm subpopulations ( $\mathrm{Y}$ or X-sperm).

The sex ratio is a complex parameter that depends on many biological and environmental factors. Preview studies have found both pre- and post-fertilization factors. Moreover, sex ratio bias may be related to both semen and the uterine environment in humans (43). Studies linking sperm quality and sex ratio are controversial. Some studies carried out in humans did not find differences in the sex ratio between seminal samples with a normal quality or with moderate or severe alterations (oligozoospermia, asthenozoospermia, and teratozoospermia) (44) or at least, this relationship is weak. However, in humans, Bae et al. (45) observed that the percentage of bicephalic sperm was significantly associated with the increase of born females. In the same way Arikawa et al. (46), using IVF, observed that samples with low sperm motility $(<40 \%)$ had a minor proportion of males compared to those samples with normal sperm motility. This variation in the sex ratio (less males) observed with lowquality semen could be associated with a lower proportion of Y-bearing sperm in the ejaculate, as suggested by Eisenberg et al. (47) in humans. Contrary, in our study the samples with lower VAP, ALH, VSL, and rapid PM increase the percentage of born males according to Mossman et al. (48) in humans. Group $\mathrm{G}$ had fewer rapid progressive sperm in vitro and this could impair the transport of X-bearing sperm in vivo. A study conducted by Balli et al. (49) in humans showed an association of higher sperm velocity in semen from patients that conceived predominantly female offsprings when compared with patients with male offsprings after assisted reproductive technology (ART) treatment.

Finally, it could be interesting to do a deep reflection about the use of antibiotics as additives in sperm extenders. As mentioned above, the reduction of using antibiotics is a worldwide concern. Among the main causes of bacterial resistance, there are some social issues such as overpopulation or global migration, but also the increasing use of antibiotics in clinics and animal production (50, 51). Recent studies carried out in boar sperm (52) are trying to optimize sperm handling protocols to avoid or reduce the use of antibiotics. Taking into account the results obtained in the present study, when using healthy semen donors under satisfactory hygiene-pathology conditions and when the samples are going to follow a frozen-thawing process, non-deleterious effects have been observed either in the sperm quality assessed in vitro or in the productive parameters (fertility, prolificacy, or fecundity) when using sperm samples without antibiotics. Our results suggest that the bacterial contamination control in frozenthawed semen may be possible without the use of antibiotics, although the effects of longer periods of cooling storage and different temperatures of storage need to be further investigated for animal semen.

\section{DATA AVAILABILITY STATEMENT}

The raw data supporting the conclusions of this article will be made available by the authors, without undue reservation.

\section{ETHICS STATEMENT}

The current study was performed according to the Guidelines of the European Union Council (86/609/EU, modified by 2010/62/EU), following Spanish regulations (RD/1201/2005, 
abrogated by $\mathrm{RD} / 2013$ ) for the use of laboratory animals. All experimental protocols and procedures were approved by the Institutional Animal Care and Use Committee at the University of León (Spain) (ÉTICA-ULE-013-2018).

\section{AUTHOR CONTRIBUTIONS}

LA-L: conceptualization, methodology, formal analysis, investigation, resources, writing-original draft, data curation, writing-review \& editing, visualization, supervision, and project administration. MR: methodology, investigation, supervision, data curation, formal analysis, and writing-review \& editing. RM-G, MN-M, JB, CC, CO-F, and JA: methodology and investigation. AC: data curation, methodology, and investigation. PP: formal analysis, investigation, resources, writing-original draft, data curation, writing-review \&

\section{REFERENCES}

1. Aurich C, Spergser J. Influence of bacteria and gentamicin on cooled-stored stallion spermatozoa. Theriogenology. (2007) 67:912-8. doi: 10.1016/j.theriogenology.2006.11.004

2. Bielanski A. Disinfection procedures for controlling microorganisms in the semen and embryos of humans and farm animals. Theriogenology. (2007) 68:1-22. doi: 10.1016/j.theriogenology.2007. 03.025

3. Auroux MR, Jacques L, Mathieu D, Auer J. Is the sperm bacterial ratio a determining factor in impairment of sperm motility: an in-vitro study in man with Escherichia coli. Int J Androl. (1991) 14:264-70. doi: 10.1111/j.1365-2605.1991. tb01091.x

4. Kaur S, Prabha V, Sarwal A. Receptor mediated agglutination of human spermatozoa by spermagglutinating factor isolated from Staphylococcus aureus. J Urol. (2010) 184:2586-90. doi: 10.1016/j.juro.2010.07.031

5. Monga M, Robertst JA. Spermagglutination by bacteria: receptor-specific interactions. J Androl. (1994) 15:151-6.

6. Diemer H, Michelmann M, Schiefer W. Escherichia coli-induced alterations of human spermatozoa. An electron microscopy analysis. Int J Androl. (2000) 23:178-86. doi: 10.1046/j.1365-2605.2000.00224.x

7. Villegas J, Schulz M, Soto L, Sanchez R. Bacteria induce expression of apoptosis in human spermatozoa. Apoptosis. (2005) 10:105-10. doi: 10.1007/s10495-005-6065-8

8. Kurpisz M, Alexander NJ. Carbohydrate moieties on sperm surface: physiological relevance. Fertil Steril. (1995) 63:15865. doi: 10.1016/S0015-0282(16)57312-9

9. EUR-Lex-31992L0065-END-EUR-Lex [WWW Document]. Available online at: https://eur-lex.europa.eu/legal-content/EN/ALL/?uri=celex: 31992L0065 (accessed April 9, 2020).

10. Yániz JL, Marco-Aguado MA, Mateos JA, Santolaria P. Bacterial contamination of ram semen, antibiotic sensitivities, and effects on sperm quality during storage at $15^{\circ} \mathrm{C}$. Anim Reprod Sci. (2010) 122:142-9. doi: 10.1016/j.anireprosci.2010.08.006

11. Gloria A, Contri A, Wegher L, Vignola G, Dellamaria D, Carluccio A. The effects of antibiotic additions to extenders on fresh and frozen-thawed bull semen. Anim Reprod Sci. (2014) 150:15-23. doi: 10.1016/j.anireprosci.2014.08.012

12. Ortega-Ferrusola C, Johannisson A, Peña Vega FJ, Tapia JA, RodriguezMartinez H, Dalin AM, et al. Effect of different extenders seminal plasma on the susceptibility of equine spermatozoa to lipid peroxidation after singlelayer centrifugation, through Androcoll-E. J Equine Vet Sci. (2011) 31:4116. doi: 10.1016/j.jevs.2011.01.010 editing, visualization, supervision, and funding acquisition. MA: conceptualization, methodology, investigation, resources, writing-original draft, data curation, writing-review \& editing, visualization, and funding acquisition. LA: conceptualization, resources, formal analysis, resources, writing-original draft, data curation, writing-review \& editing, visualization, supervision, project administration, and funding acquisition. All authors contributed to the article and approved the submitted version.

\section{FUNDING}

The authors acknowledge the JCyL-LE253P18 research contract and ORDEN EDU/556/2019 fellowship (Junta Castilla y León), FPU17/04142 (MCIU) and PRE2018-086400 (MEC) fellowships, the ITRA-ULE technicians (Ainoa Jordán, Pedro de Vega and Cecilia Pérez), ANCHE and the staff from Ovigén.

13. Schulze $M$, Grobbel $M$, Riesenbeck A, Brüning S, Schaefer J, Jung $M$ et al. Dose rates of antimicrobial substances in boar semen preservationtime to establish new protocols. Reprod Domest Anim. (2017) 52:397402. doi: 10.1111/rda.12921

14. Anel-López L, García-Álvarez O, Parrilla I, Del Olmo D, Maroto-Morales A, Fernandez-Santos MRR, et al. Effect of sex-sorting and cryopreservation on the post-thaw sperm quality of iberian red deer spermatozoa. Theriogenology. (2017) 89:206-13. doi: 10.1016/j.theriogenology.2016. 11.010

15. López-Urueña E, Alvarez M, Gomes-Alves S, Manrique P, Anel-López L, Chamorro CA, et al. Alternative procedures for the cryopreservation of brown bear ejaculates depending on the flexibility of the "in cooling" period $\left(5^{\circ} \mathrm{C}\right)$. Cryobiology. (2014) 69:434-41. doi: 10.1016/j.cryobiol.2014.10.001

16. Azawi OI, Ismaeel MA. Influence of addition of different antibiotics in semen diluent on viable bacterial count and spermatozoal viability of awassi ram semen. Vet World. (2012) 5:75-9. doi: 10.5455/vetworld.2012.75-79

17. Madeira E, Goularte K, Pradieé J, Mondadori R, Lucia J, Bianchi I, et al. The use of antibiotics in cryopreservation of ram sperm. Int J Vet Med Res Reports. (2014) 2014:154947. doi: 10.5171/2014.154947

18. Varner DD, Scanlan CM, Thompson JA, Brumbaugh GW, Blanchard TL, Carlton CM, et al. Bacteriology of preserved stallion semen and antibiotics in semen extenders. Theriogenology. (1998) 50:559-73. doi: 10.1016/S0093-691X(98)00161-7

19. Akhter S, Ansari MS, Andrabi SMH, Ullah N, Qayyum M. Effect of antibiotics in extender on bacterial and spermatozoal quality of cooled buffalo (Bubalus bubalis) bull semen. Reprod Domest Anim. (2008) 43:2728. doi: 10.1111/j.1439-0531.2007.00890.x

20. Althouse GC, Kuster CE, Clark SG, Weisiger RM. Field investigations of bacterial contaminants and their effects on extended porcine semen. Theriogenology. (2000) 53:1167-76. doi: 10.1016/S0093-691X(00) 00261-2

21. Maes D, Nauwynck H, Rijsselaere T, Mateusen B, Vyt P, de Kruif A, et al. Diseases in swine transmitted by artificial insemination: an overview. Theriogenology. (2008) 70:1337-45. doi: 10.1016/j.theriogenology.2008.06.018

22. Maroto Martín LO, Muñoz EC, De Cupere F, Van Driessche E, Echemendia-Blanco D, Rodríguez JMM, et al. Bacterial contamination of boar semen affects the litter size. Anim Reprod Sci. (2010) 120:95-104. doi: 10.1016/j.anireprosci.2010.03.008

23. Aslam B, Wang W, Arshad MI, Khurshid M, Muzammil S, Rasool MH, et al. Antibiotic resistance: a rundown of a global crisis. Infect. Drug Resist. (2018) 11:1645-58. doi: 10.2147/IDR.S173867

24. Anel L, de Paz P, Alvarez M, Chamorro C, Boixo J, Manso A, et al. Field and in vitro assay of three methods for freezing ram semen. Theriogenology. (2003) 60:1293-308. doi: 10.1016/S0093-691X(03)00140-7 
25. Alvarez M, Chamorro CAA, Kaabi M, Anel-Lopez L, Boixo JCC, Anel E, et al. Design and "in vivo" evaluation of two adapted catheters for intrauterine transcervical insemination in sheep. Anim Reprod Sci. (2012) 131:153-9. doi: 10.1016/j.anireprosci.2012.03.001

26. Morrell JM, Wallgren M. Alternatives to antibiotics in semen extenders: a review. Pathogens. (2014) 3:934-46. doi: 10.3390/pathogen 3040934

27. Bjurström L, Linde-Forsberg C. Long-term study of aerobic bacteria of the genital tract in stud dogs. Am J Vet Res. (1992) 53:670-3.

28. Clément F, Vidament $\mathrm{M}$, Guérin B. Microbial contamination of stallion semen. Biol Reprod. (1995) 52:77986. doi: 10.1093/biolreprod/52.monograph_series1.779

29. Jasko DJ, Bedford SJ, Cook NL, Mumford EL, Squires EL, Pickett BW. Effect of antibiotics on motion characteristics of cooled stallion spermatozoa. Theriogenology. (1993) 40:885-93. doi: 10.1016/0093-691X(93) 90356-A

30. Vasan SS. Semen analysis and sperm function tests: how much to test? Indian J Urol. (2011) 27:41-48. doi: 10.4103/0970-1591.78424

31. Zhao Y, Vlahos N, Wyncott D, Petrella C, Garcia J, Zacur H, et al. Impact of semen characteristics on the success of intrauterine insemination. J Assist Reprod Genet. (2004) 21:143-8. doi: 10.1023/B:JARG.0000031246.76666.f6

32. Riesco MF, Anel-Lopez L, Neila-Montero M, Palacin-Martinez C, MontesGarrido R, Alvarez M, et al. ProAKAP4 as novel molecular marker of sperm quality in ram: an integrative study in fresh, cooled and cryopreserved sperm. Biomolecules. (2020) 10:1046. doi: 10.3390/biom 10071046

33. Huang Z, Somanath PR, Chakrabarti R, Eddy EM, Vijayaraghavan S. Changes in intracellular distribution and activity of protein phosphatase PP1 $\gamma 2$ and its regulating proteins in spermatozoa lacking AKAP41. Biol Reprod. (2005) 72:384-92. doi: 10.1095/biolreprod.104.034140

34. Pereira R, Sá R, Barros A, Sousa M. Major regulatory mechanisms involved in sperm motility. Asian J Androl. (2017) 19:5-14. doi: 10.4103/1008-682X.167716

35. Rahamim Ben-Navi L, Almog T, Yao Z, Seger R, Naor Z. A-Kinase anchoring protein 4 (AKAP4) is an ERK1/2 substrate and a switch molecule between cAMP/PKA and PKC/ERK1/2 in human spermatozoa. Sci Rep. (2016) 6:37922. doi: $10.1038 /$ srep37922

36. Fang X, Huang LL, Xu J, Ma CQ, Chen ZH, Zhang Z, et al. Proteomics and single-cell RNA analysis of Akap4-knockout mice model confirm indispensable role of Akap4 in spermatogenesis. Dev Biol. (2019) 454:11827. doi: 10.1016/j.ydbio.2019.06.017

37. Kwon WS, Oh SA, Kim YJ, Rahman MS, Park YJ, Pang MG. Proteomic approaches for profiling negative fertility markers in inferior boar spermatozoa. Sci Rep. (2015) 5:13821. doi: 10.1038/srep 13821

38. Sengupta S, Chattopadhyay MK, Grossart HP. The multifaceted roles of antibiotics and antibiotic resistance in nature. Front Microbiol. (2013) 4:47. doi: 10.3389/fmicb.2013.00047

39. Spellberg B, Gilbert DN. The future of antibiotics and resistance: a tribute to a career of leadership by John Bartlett. Clin Infect Dis. (2014) 59:S715. doi: 10.1093/cid/ciu392

40. Aleem M, Chaudhry R, Khan N, Rizvi A, Ahmad R. Occurrence of pathogenic bacteria in buffalo semen. Buffalo J. (1990) 6:93-8.
41. Waberski D, Weitze KF, Meding S, Leiding C, Weiskopf S. Examination on sperm- and fertility-compatibility of lincospectinsterile solution as antibiotic additive in liquid boar semen. Reprod Domest Anim. (1990) 25:2915. doi: 10.1111/j.1439-0531.1990.tb00476.x

42. Korchunjit W, Kaeoket K, Kitiyanant Y, Taylor J, Wongtawan T. Defined combinations of cryomedia and thawing extenders influence the viable $\mathrm{X}-\mathrm{Y}$ boar sperm ratio in vitro. Cryo Lett. (2017) 38:160-5.

43. Graffelman J, Fugger EF, Keyvanfar K, Schulman JD. Human live birth and sperm-sex ratios compared. Hum Reprod. (1999) 14:29179. doi: 10.1093/humrep/14.11.2917

44. Jacobsen R, Bostofte E, Skakkebæk NE, Hansen J, Møller H. Offspring sex ratio of subfertile men and men with abnormal sperm characteristics. Hum Reprod. (2000) 15:2369-70. doi: 10.1093/humrep/15.11.2369

45. Bae J, Kim S, Chen Z, Eisenberg ML, Buck Louis GM. Human semen quality and the secondary sex ratio. Asian J Androl. (2016) 18:37481. doi: 10.4103/1008-682X.173445

46. Arikawa M, Jwa SC, Kuwahara A, Irahara M, Saito H. Effect of semen quality on human sex ratio in in vitro fertilization and intracytoplasmic sperm injection: An analysis of 27,158 singleton infants born after fresh single-embryo transfer. Fertil Steril. (2016) 105:897-04. doi: 10.1016/j.fertnstert.2015.12.009

47. Eisenberg ML, Murthy L, Hwang K, Lamb DJ, Lipshultz LI. Sperm counts and sperm sex ratio in male infertility patients. Asian J Androl. (2012) 14:683-6. doi: 10.1038/aja.2012.58

48. Mossman JA, Slate J, Birkhead TR, Moore HD, Pacey AA. Sperm speed is associated with sex bias of siblings in a human population. Asian J Androl. (2013) 15:152-4. doi: 10.1038/aja.2012.109

49. Balli KS, Patton WC, Jacobson JD, Corselli J, King A, Chan PJ. Sperm velocity in seminal plasma and the association with gender of offspring. Arch Androl. (2004) 50:37-40. doi: 10.1080/01485010490250560

50. Marshall BM, Levy SB. Food animals and antimicrobials: Impacts on human health. Clin Microbiol Rev. (2011) 24:718-33. doi: 10.1128/CMR.00002-11

51. Singer AC, Shaw H, Rhodes V, Hart A. Review of antimicrobial resistance in the environment and its relevance to environmental regulators. Front Microbiol. (2016) 7:1728. doi: 10.3389/fmicb.2016.01728

52. Waberski D, Luther AM, Grünther B, Jäkel H, Henning H, Vogel $\mathrm{C}$, et al. Sperm function in vitro and fertility after antibiotic-free, hypothermic storage of liquid preserved boar semen. Sci Rep. (2019) 9:14748. doi: 10.1038/s41598-019-51319-1

Conflict of Interest: The authors declare that the research was conducted in the absence of any commercial or financial relationships that could be construed as a potential conflict of interest.

Copyright (C) 2021 Anel-Lopez, Riesco, Montes-Garrido, Neila-Montero, Boixo, Chamorro, Ortega-Ferrusola, Carvajal, Altonaga, de Paz, Alvarez and Anel. This is an open-access article distributed under the terms of the Creative Commons Attribution License (CC BY). The use, distribution or reproduction in other forums is permitted, provided the original author(s) and the copyright owner(s) are credited and that the original publication in this journal is cited, in accordance with accepted academic practice. No use, distribution or reproduction is permitted which does not comply with these terms. 